\title{
Analisis Waktu Tunggu Pelayanan Terhadap Kepuasan Pasien Di RSUD Cempaka Putih Tahun 2020
}

\author{
Sarah Fauziyyah \\ Universitas Respati Indonesia \\ sara.fara95@gmail.com
}

\begin{abstract}
Abstrak
Latar Belakang : Sikap dan perilaku petugas sering ditemukan sangat berkaitan dengan ketidak puasnya pasien. Pelayanan yang merupakan waktu tunggu yaitu dari saat pasien mulai dari tempat pendaftaran sampai memasuki ruang pemeriksaan dokter untuk mendapatkan pelayanan kesehatan. Untuk mengetahui hubungan waktu tunggu dengan kepuasan pasien tujuan dari penelitian ini. Metode : Kuantatif dengan deskriptif yang di gunakan pada penelitian ini dengan teknik pengumpulkan data yang berupa informan di wawanccara secara mendalam kemudian obervasi, bagian pendaftaran, dokter dan perawat perupakan informan dari penelitian. Hasil : Bekerja sudah sesuai tugas masing-masing pada bagian petugas pendaftaran hanya masih sistem manual yang di gunakan pendaftar pada rumah sakit tersebut salah satunya faktor yang membuat lama waktu pasien di rawat jalan serta terjadi faktor lain yaitu tidak sesuainya jam praktek dokter sangat mempengaruhi lamanya waktu tunggu dan kepuasan pasien. Kesimpulan dan Saran : Peneliti melakukan wawancara dan observasi dan berdasarkan hasil yang dilakukan terdapat hubungan antara waktu tunggu pelayanan terhadap kepuasan pasien di RSUD Cempaka putih. Apek seluruh mutu pada pelayanan harus ditingkatkan supaya tercipta kepuasan pasien $\geq 90 \%$ dengan kepmenkes sesuai standar tentang pelayanan minimal rumah sakit.
\end{abstract}

Kata Kunci : Kepuasan, Waktu Tunggu Pelayanan

\begin{abstract}
Abstrak
Background: The attitude and behavior of officials are often found very related to the lack of satisfaction of patients. Service which is a waiting time, namely from the time the patient starts from the registration place until he enters the doctor's examination room to get health services. To find out the waiting time relationship with patient satisfaction the aim of this study. Methods : qualitative with descriptive that is in use in research is the technique pengumpulkan data in the form of informant interviews in depth later observation, part of the registration, the doctor and nurse is a informants of the study. Results : Work already corresponding duties respectively on section officer registration only is the system manual in use registries at home sick of the one only factor which makes long time patients in ambulatory street and happened factor else that is not incompatibility of hours practice physicians highly affect the length of time wait and patient satisfaction. Conclusions and Suggestions : Researchers conduct interview and observations and based on resluts that do are an association between the time waiting for service to the satisfaction of patient in hospitals Cempaka Putih. Aspek whole quality of the service must be improved in order to create the saticfaction of patients $90 \%$ by kepmenkes appropriate standard of service minimal home sick.
\end{abstract}

Keywords : Satisfaction, Service Waitime Time 


\section{PENDAHULUAN}

Menurut WHO, Organisasi sosial dengan bagian yang menyeluruh dengam medis yang berfungsi memberikan secara lengkap mengenai pelayanan kesehatan untuk masyarakat secara kuratif ataupun rehabilitatif adalah Rumah Sakit. Pelayanan kesehatan yang diberikan Rumah yaitu membuat informasi kesehatan dari setiap fasilitas kesehatan karena sebagai kewajiban dan tanggung jawab. Profesi rekam medis di perlukan sebagai penyedia informasi pengumpulan data awal pasien menyampaikan informasi kesehatan (Sobrina, 2011).

Rawat jalan merupakan salah satu dari bentuk pelayanan yang ada di Rumah Sakit. Pelayanan medis terhadap pasien yang tidak lebih dari 24 jam ialah rawat jalan bertujuan untuk pengobatan, pengamatan diagnosis, rehabilitasi tanpa pasien menginap dan pelayanan kesehatan yang lainnya. Sumber daya yang ada di rumah sakit seperti pelayanan dokter, perawat, staf/karyawan, keamanan lingkungan dan juga fasilitas sarana dan prasarana sangat bergantung pada kualitas rumah sakit.

Ketidak puasan pasien sering ditemukan dalam pengalaman sehari-hari berkaitan dengan sikap dan perilaku petugas, contohnya seperti : dokter yang sulit temui, keterlambatan pelayanan perawat dan dokter, dokter kurang informatif dan komunikatif, aspek pelayanan, proses masuk rawat jalan yang lama, kebersihan lingkungan dan ketertiban rumah sakit.

Pasien datang dengan mendaftaran dirinya di bagian pendaftaran sampai pasien masuk di periksakan oleh dokter merupakan waktu tunggu pelayanan. (Kapustiak, 2000). Indikator waktu tunggu pelayanan rawat jalan yaitu 60 menit dari pasien datang untuk mendaftarkan diri sampai pasien di terima dan di layani oleh dokter spesialis berdasarkan Kepmenkes RI No.129/Menkes/SK/IV/2008.

Berdasarkan hasil pendahuluan yang telah dilakukan oleh peneliti melalui wawancara terkait waktu tunggu pelayanan pasien rawat jalan dan melakukan observasi atau pengamatan di RSUD Cempaka Putih didapatkan masalah yaitu waktu tunggu pada saat pelayanan dokter yang terlambat (1-2 jam) dan sistem pendaftaran pasien masih manual. Terkait hal tersebut sehingga menyebabkan waktu tunggu pelayanan pasien di rawat jalan sendiri masih belum berjalan dengan baik.

\section{METODE}

Jenis penelitian ini adalah kualitatif deskriptif, data yang dikumpulkan berbentuk kata-kata, gambar, bukan angka. Dilakukannya penelitian di rawat jalan dari pasien mendaftarkan diri di bagian pendaftaran sampai di terima oleh dokter poliklinik. Penelitian dilakukan di Unit Rawat Jalan RSUD Cempaka Putih, Jakarta Pusat. Informan pada penelitian ini adalah dokter spesialis, perawat, petugas pendaftaran dan pasien. Cara pengambilan data observasi lapangan dilakukan untuk mengetahui waktu tunggu pelayanan rawat jalan dan factor apa saja yang mempengaruhi waktu tunggu

\section{HASIL}


Informan pada penelitian ini terdiri dari 3 dokter, 3 perawat, 1 petugas pendaftaran dan 30 pasien.

\section{Sistem Pendaftaran}

Pertanyaan : Gambaran Sistem Pendaftaran di Unit Rawat Jalan RSUD Cempaka Putih?

Jawab : "...Pendaftaran di rumah sakit cukup baik masih bisa mengcover dan melayani pasien mendaftar hanya saja sering mengalami keterlambatan..." (Informant)

\section{Rawat Jalan}

Pertanyaan 1 : Faktor penyebab terjadinya lama waktu tunggu rawat jalan?

Jawab : "... Beberapa dokter poliklinik ada yang datang terlambat ini salah satu penyebab lama nya waktu tunggu ..." (Informant)

Pertanyaan 2 : Dokter datang tepat waktu sesuai jadwal yang sudah ditentukan?

Jawab : "... Kalau tidak ada kesibukan lain mungkin tidak sesuai dengan jadwal yang sudah ditentukan bisa saja saya telat ..." (Informant)

Pertanyaan 3 : Dokter praktek di tempat lain selain di RSUD Cempaka Putih?

Jawab : "... Kalau saya praktek ditempat lain juga selain praktek disini ..."(Informant)

Pertanyaan 4 : Berapa lama dokter praktek di RSUD Cempaka Putih?

Jawab : "... Dokter yang praktek disini lebih dari 1 tahun ..." (Informant)

Pertanyaan 5 : Sarana Prasarana unit rawat jalan sudah mendukung untuk cepatnya pelayanan

Jawab : "... Untuk di rawat jalan sudah mendukung, hanya mungkin di pendaftaran sebagiknya menggunakan sistem online agar lebih cepat lagi ..."(Informant)

Pertanyaan 6 : SPM Rumah Sakit mengenai waktu tunggu rawat jalan?
Jawab : "... dari mulai pasien mendaftar sampai diterima dokter 60 menit, tapi terkadang mengalami keterlambatan jadi lebih dari 60 menit ..." (Informant)

Pertanyaan 7 : SPO tentang waktu tunggu rawat jalan?

Jawab : "... SPO sudah kami terapkan tetapi untuk pelaksanaannya belum sesuai ..." (Informant)

Pertanyaan 8 : Dampak waktu tunggu rawat lama?

Jawab : "... Banyak pasien komplen karena terlalu lama menunggu ..." (Informant)

Pertanyaan 9 : Berkas rekam medis turun ke perawat?

Jawab : "... rekam medis sduah menggunakan sistem sebelum pasien naik rekamedis sudah turun ..." (Informant)

Pertanyaan 10 : SDM unit rawat jalan sudah mencukupi?

Jawab : SDM bagian pendaftaran, perawat dan dokter sudah mencukupi (Informant)

Pertanyaan 11 : Pendaftaran pasien dibuka?

Jawab : "... pasien jam 5 pagi sudah mendaftarkan diri secara manual kita memberikan form untuk di isi seperti nama, tujuan poli, no rekam medis untuk pasien baru dan pasien lama cukup nama saja, kemudian jam 05.30 mengambil nomor antrian ..." (Informant)

Pertanyaan 12 : Pendaftaran pasien baru dan pasien lama?

Jawab : "... Perbedaannya hanya di kartu berobat. Jika pasien lama biasanya mempunyai kartu berobat kalau pasien baru tidak memiliki kartu berobat ..." (Informant)

Pertanyaan 13 : Pendaftaran pasien umum dan bpjs

Jawab : "... Tidak ada perbedaan antara pasien umum dan bpjs ..." (Informant)

Pertanyaan 14 : Nomor Antrian 
Jawab : "... Untuk pasien lama setelah menunjukan kartu berobat bisa mengambil nomor antrian, untuk pasien baru harus mengisi form pasien baru tersebut kemudian baru bisa mengambil nomor antrian ..." (Informant)

Pertanyaan 15 : Petugas bagian pendaftaran?

Jawab : "... Petugas pendaftaran kami sudah tercukupi, dan sudah bekerja sesuai tupoksinya masing-masing ..." (Informant)

\section{Hasil Observasi Waktu Tunggu Pelayanan Rawat Jalan}

Dari jumlah 30 pasien total pasien waktu tunggu yang menyatakan < 100 menit sebanyak 19 pasien dan $>100$ menit sebanyak 11 pasien di Unit Rawat Jalan RSUD Cempaka Putih.

Wawancara Kepuasan Pasien Rawat Jalan RSUD Cempaka Putih

1. Petugas pendaftaran memberitahu alur rawat jalan

Dari jumlah 30 responden menyatakan petugas memberitahu sistem alur rawat jalan Unit Rawat Jalan RSUD Cempaka Putih

2. Pelayanan di unit rawat jalan sudah sesuai dengan alur yang ada

\section{KESIMPULAN}

1. Penyebab lamanya waktu tunggu di instansi rawat jalan RSUD Cempaka Putih disebabkan beberapa faktor antara lain : keterlambatan dokter saat memulai pelayanan karena tidak sesuai jadwal praktek yang telah di tentukan rumah sakit dan lama waktu tunggu terjadi di bagian pendaftaran karena sistem pendaftaran di RSUD Cempaka Putih masih manual.

2. Didapatkan hasil bahwa sebagian besar responden merasa puas dengan pelayanan yang telah diberikan rumah sakit tetapi ada beberapa aspek yang di fasa kurang
Dari jumlah 30 responden menyatakan pelayanan di unit rawat jalan sudah sesuai dengan alur yang ada

\section{Merasa puas dengan fasilitas di ruang} tunggu unit rawat jalan

Dari jumlah 30 responden di antaranya 20 menyatakan (puas) dan 10 menyatakan (cukup puas) dengan fasilitas di unit rawat jalan tersebut

4. Dokter/perawat selalu meyampaikan hasil pemeriksaan

Dari jumlah 30 responden menyatakan dokter/perawat selalu menyampaikan hasil pemeriksaan di Unit Rawat Jalan RSUD Cempaka Putih

5. Petugas di unit rawat jalan menerima masukan dan keluhan pasien dengan baik

Dari jumlah 30 responden menyatakan petugas menerima masukan dan keluhan pasien dengan baik.

\section{Pasien dibiarkan menunggu lama oleh petugas}

Dari 30 responden menyatakan 7 responden menunggu lama di bagian pendaftaran dan 23 responden mengatakan menunggu lama saat dokter memulai praktek.

terutama pada bagian pendaftaran dan pada saat menunggu dokter.

3. Berdasarkan hasil wawancara dan observas yang dilakukan peneliti terdapat hubungan antara waktu tunggu pelayanan dengan kepuasan pasien di RSUD Cempaka Putih

\section{Saran}

1. Dilakukan evaluasi dan monitoring jadwal praktek dokter di RSUD Cempaka Putih agar tidak terjadi keterlambatan dokter saat memulai jam pelayanan dan untuk bagian pedaftaran sebaiknya 
menggunakan sistem online dari pasien mendaftarkan diri, mengambil nomor antrian sampai memilih dokter poliklinik agar mempercepat proses pelayanan rawat jalan

2. Meningkatkan kualitas layanan pada aspek perlakukan personal terutama dari petugas pendaftaran dan dokter agar pasien merasa puas atas pelayanan yang rumah sakit berikan tanpa harus menunggu lama

3. Meningkatkan seluruh aspek mutu pelayanan agar terciptanya kepuasan pasien $\geq 90 \%$ sesuai dengan kepmenkes tentang standar pelayanan minimal rumah sakit.

\section{DAFTAR PUSTAKA}

1. Arieta R. Analisis Waktu Tunggu Pasien di Departeman Gigi dan Mulut RSPAD Gatot Soebroto Ditkesad Tahun 2011.

2. Fakultas Kesehatan Masyarakat,Tesis.Jakarta: Program Studi Kajian Administrasi Rumah Sakit Universitas Indonesia; 2012.

3. Esti A. Pengaruh Waktu Tunggu dan Waktu Sentuh Pasien terhadap Tingkat Kepuasan Pasien Poli Umum di Puskesmas Sukorame Kota Kediri. Publikasi.stikesstrada.ac.id. diakses pada 3 maret 2017

1. Gde Muninjaya, A.A. 2015. Manajemen Mutu Pelayanan Kesehatan Edisi 2 Jakarta, ECG

2. Menteri Kesehatan RI. 2008. NOMOR : 129/Menkes/SK/II/2008 tentang standar pelayanan minimal rumah sakit

3. Neti M. Bustani. 2015. Analisis Lama Waktu Pelayanan Pasien Rawat Jalan di Balai Kesehatan
Mata Masyarakat Propinsi Sulawesi Utara.

4. Utami Yeni Tri., Jurnal Hubungan Waktu Tunggu Pelayanan Rawat Jalan dengan Tingkat Kepuasan Pasien di RSU Assalam Gemolong. Apikes Citra Medika. Surakarta

5. Kumbayono dkk, 2013, Pengaruh lama waktu tunggu terhadap tinggkat kepuasan pada pasien rawat jalan di Puskesmas Dinoyo Kota Malang tahun 2013, Fakultas Kedokteran Universitas Brawijaya.

6. Diakses tanggal 05 Desember 2013, dari

old.fk.ub.ac.id/artikel/id/filedownlo ad/keperawatan/Riza\%20Tafzani.p $\underline{\mathrm{df}}$

7. Nurlaelyah, 2017. Waktu Tunggu Pelayanan Rawat Jalan dengan Kepuasan Pasien Terhadap Pelayanan Rawat Jalan RSUD Kabupaten Indramayu

8. Supranto, J. 2011. Pengukur Tingkat Kepuasan Pelanggan, Jakarta

9. Irawan H. 10 Prinsip Kepuasan Pelanggan. Jakarta Gramedia ; 2009.

10. Endang Ernawati, 2018. Waktu Tunggu Pelayanan Rawat Jalan Dengan Tingkat Kepuasan Pasien RSUD dr. Doris Sylvanus 
11. Yulfa Yulia, 2017. Hubungan Waktu Tunggu Pelayanan Rawat Jalan Dengan Kepuasan Pasien Spesialis Pribadi di Rumah Sakit Atma Jaya

12. Nofriadi, 2019. Hubungan Lama Waktu Pelayanan Dengan Kepuasan Pasien Poli Penyakit Dalam RSUD Painan

13. Dedi Fatrida, 2019. Hubungan Waktu Tunggu Dengan Tingkat Kepuasan Pasien Dalam Mendapatkan Pelayanan Kesehatan

14. Muthiah Rissa Pratiwi, 2017. Hubungan Waktu Tunggu Pelayanan Terhadap Tingkat Kepuasan di Poliklinik Kebidanan dan Kandungan RSUD Kota Surakarta

15. Fetter,Robert B, John D Thompson. Patient Waiting And Doctor's Idle Time in The Out Patient Setting. Journal Of Health Services Research Summer.Vol.1,p.66.Simmer,1996

16. (http://www.ncbi.nlm.noh.gov/pmc /articles/PMCO1067302/)diakses tanggal 25 September 2015)

17. Sudarwan Danim, Menjadi Peneliti Kualitatif Rancangan Metodologi, Presentasi, dan Publikasi Hasil Penelitian untuk Mahasiswa dan
Penelitian Pemula Bidang Ilmu Sosial, Pendidikan, dan Humaniora, (Bandung: Remaja Rosdakarya, 2002), Cet. I, hlm. 51. 18. Lexy. J. Moleong, Metodologi Penelitian Kualitatif, (Bandung: PT Remaja Rosdakarya, 2000)

19. Ratma W. Faktor-Faktor yang Berhubungan dengan Responsiveness Pelayanan Kesehatan Rawat Jalan Puskesmas Gambir 2010

20. Sinaga, Alvin, dkk (2012). Tingkat Kepuasan Orang Tua Pasien di Pediatri Rawat Jalan Departemen Ilmu Kesehatan Anak Rumah Sakit Umum Pusat Dr. Cipto Mangnkusumo (Jakarta. 2006)

21. Suharsimi Arikunto, Prosedur Penelitian Suatu Pendekatan Praktek, (Jakarta : PT. Rineka Cipta, 2002, Cet.XII)

22. Sugiyono, Metode Penelitian Pendidikan Pendekatan Kuantitatif, Kualitatif, dan R\&D, (Bandung: Alfabeta, 2008)

23. Sudarto, Metodologi Penelitian Filsafat, (Jakarta: Raja Grafindo Persada, 1997), hlm. 66.

24. Stoop AP, Vrangbaek K, Berg M. Theory and practice of waiting time data as a performance indicator in 
health care : A case study from the Neterland. Health Policy 2005

25. Husaini Usman dan Purnomo Setiadi Akbar, Metodologi
Penelitian Sosial, (Jakarta: PT Bumi Aksara, 2009) 